Uganda Journal of Agricultural Sciences by National Agricultural Research Organisation is licensed under a Creative Commons Attribution 4.0 International License.

Based on a work at www.ajol.info

\title{
Trends in variability and extremes of rainfall and temperature in the cattle corridor of Uganda
}

\author{
B. Owoyesigire ${ }^{1,2}$, D. Mpairwe ${ }^{1}$, P. Ericksen ${ }^{3}$ and D. Peden ${ }^{4}$ \\ ${ }^{1}$ Department of Agricultural Production, School of Agricultural Sciences, \\ College of Agricultural and Environmental Sciences (CAES), Makerere University, \\ P. O. Box 7062, Kampala, Uganda \\ ${ }^{2}$ Buginyanya Zonal Agricultural Research and Development Institute (BugiZARDI),Uganda \\ ${ }^{3}$ International Livestock Research Institute ILRI, P. O. Box 37009, Nairobi, Kenya \\ ${ }^{4}$ International Livestock Research Institute ILRI, P. O. Box 5689, Addis Ababa, Ethiopia
}

Author for correspondence: bowoyesigire@ caes.mak.ac.ug, budiikubrian@yahoo.com

\begin{abstract}
A study was conducted to determine trends of variability and extremes in rainfall and temperature in order to inform stakeholder's decisions in planning for appropriate adaptation strategies to climate change. Daily rainfall and temperature data sets from 1961 to 2013 were used. Data were subjected to trend analysis using non-parametric Mann-Kendall tests while rainfall and temperature extremes were derived using RClimdex software. Coefficient of variation $(\mathrm{CV})$ in annual rainfall was 25.3, 12.9 and 16.3 \% for Mbarara, Masindi and Soroti respectively. Mean daily maximum temperatures were $26.7,29.6$ and $30.8{ }^{\circ} \mathrm{C}$ for Mbarara, Masindi and Soroti respectively. Annual total wet days were increasing but not significant $(\mathbf{P}>\mathbf{0 . 0 5}$ ). Consecutive wet days (CWD) were increasing only in Mbarara while consecutive dry days, CDDs revealed weak declining trends in Mbarara and stronger significant increasing trends in Soroti $(P<0.05)$. The number of hot days (TX90p) and warm nights (TN90p) was significantly increasing $(P<0.05)$ in Mbarara and Masindi. The number of warmest nights $(\mathbf{T N x})$ and hottest days $(\mathrm{TXx})$ was also significantly increasing $(\mathbf{P}<0.05)$. Mean diurnal temperature range, DTR showed significant decreasing trends in Mbarara and Masindi $(\mathbf{P}<0.05)$ while in Soroti it was significantly increasing. The observed increasing temperatures, coupled with declining CWDs and increasing CDDs will most likely result into increased heat stress to livestock, drying of most surface water sources and changes in pasture species composition thus causing a decline in livestock productivity.
\end{abstract}

Key words: Climate change and cattle corridor, hot days, trends, wet days 


\section{Introduction}

Climate change is one of the key challenges facing the human race in the $21^{\text {st }}$ century due to increased emissions of green house gases (GHG) such as carbon dioxide, methane and nitrous acid (IPCC, 2001). Climate variability and changes in extreme weather have significant impacts and are among the most serious challenges to society in coping with a changing climate (CCSP, 2008). Toreti and Desiato (2008), further observes that climate change is characterized by variations of climatic variables in mean and extreme values. Climate extremes are unusual weather events in their occurrence which always lie in the upper or lower ten percentile of the distribution and have destructive potential like hurricanes, tornadoes, hailstorms, very heavy rainfall and heat waves for long period of time (CCSP, 2008). Therefore extreme climatic events have strong impact on society and ecosystems and are thus important to study (Moberg and Jones, 2005). In Uganda, the cattle corridor must get concerned of rainfall and temperature (climate) extremes because it's considered among the most fragile regions in the country (NEMA, 2001). Livestock which solely depend on grazing of natural pastures are the main contributors to survival of livelihoods in the cattle corridor. Most common livestock species kept include cattle, goats, and sheep. Availability of natural pastures for grazing in the cattle corridor is directly influenced by the amount of rainfall recieved and the prevailing ambient temperatures (MLWE, 2003). However, climate change which manifests as increased droughts and floods has continued to depress livestock production in the region.
Reducing climate change impacts on productivity of the cattle corridor region could be achieved through reducing exposure to hazardous conditions and/or through enhancing adaptive capacity to better deal with or manage hazardous conditions. Adaptation to climate change is defined as an adjustment in natural or human systems in response to actual or expected climatic stimuli or their effects, which moderates harm or exploits beneficial opportunities (IPCC, 2001). Therefore increasing livestock productivity in the cattle corridor means enhanced adaptation to climate change. Studies at a broad scale have attempted to characterise East African rainfall variability and have reported an increase in total amount of annual rainfall (Nimusiima, et al, 2013; Thornton et al., 2009 and Nicholson, 1993). However, the equatorial Eastern Africa rainfall is very complex and mostly regionally controlled, implying that generalities basing on global climatic patterns can not be relied upon (Nicholson,1996). Therefore attention must be paid to investigate trends of rainfall and temperature characteristics at very fine local scales to inform the process of adaptation with certainity. Moreover, understanding how precipitation and temperature extremes are changing is important in planning appropriate adaptation measures since they have major impacts to society. However, information on how climate extremes are changing in the fragile cattle corridor region is not yet well established. The aim of this study is to provide a better understanding of the changes in the variability and trends of climate extreme events across the cattle corridor using daily temperature and precipitation extreme indices in order to inform the process of 
developing appropriate adaptation strategies to climate change.

\section{Materials and methods}

\section{The study area}

The cattle corridor (Uganda's rangelands) is an area of $84,000 \mathrm{~km}^{2}$ running from the southwest, Rwanda boarder to the Sudan/ Somalia/Kenya boarder in the Northeastern direction. It covers (fully or partially) several districts in the country such as Kotido, Moroto, Katakwi and Soroti in the North east; Nakasongola and parts of Luwero in the central to Rakai, Mbarara and Ntungamo in the South west. About 6.6 million people dwell in this region (UBOS, 2002). The region accounts for about $90 \%$ of the national livestock herd contributing about $85 \%$ and $95 \%$ of the milk and beef consumed respectively (King, 2002). The area is also characterized by a semi arid climate with a bi-modal rainfall pattern. The first rainy season occurs in the months of March-
May while the second is SeptemberNovember. The dominant vegetation cover ranges from grasses interspersed with trees, to forest savannah mosaics and woodland in some areas, and a high susceptibility to changes in land use (NEMA, 2001). Mixed production systems comprising of nomadic pastoralists, agropastoralists and subsistence farmers are among the prevailing systems sustaining livelihoods

\section{Data collection}

Daily rainfall and temperature data sets from 1961 to 2013 were used. Data of 11 stations spread across the cattle corridor were obtained from the National Meteorological Authority (NMA) in Kampala. These stations included; Mbarara, Ruherengeri, Lyantonde, Kiruhura, Sembabule, Luwero, Kakooge, Nakasongola, Masindi, Soroti and Kotido. During civil political arrests in the 1970's and 1980's most of these weather stations were run down and could not record any

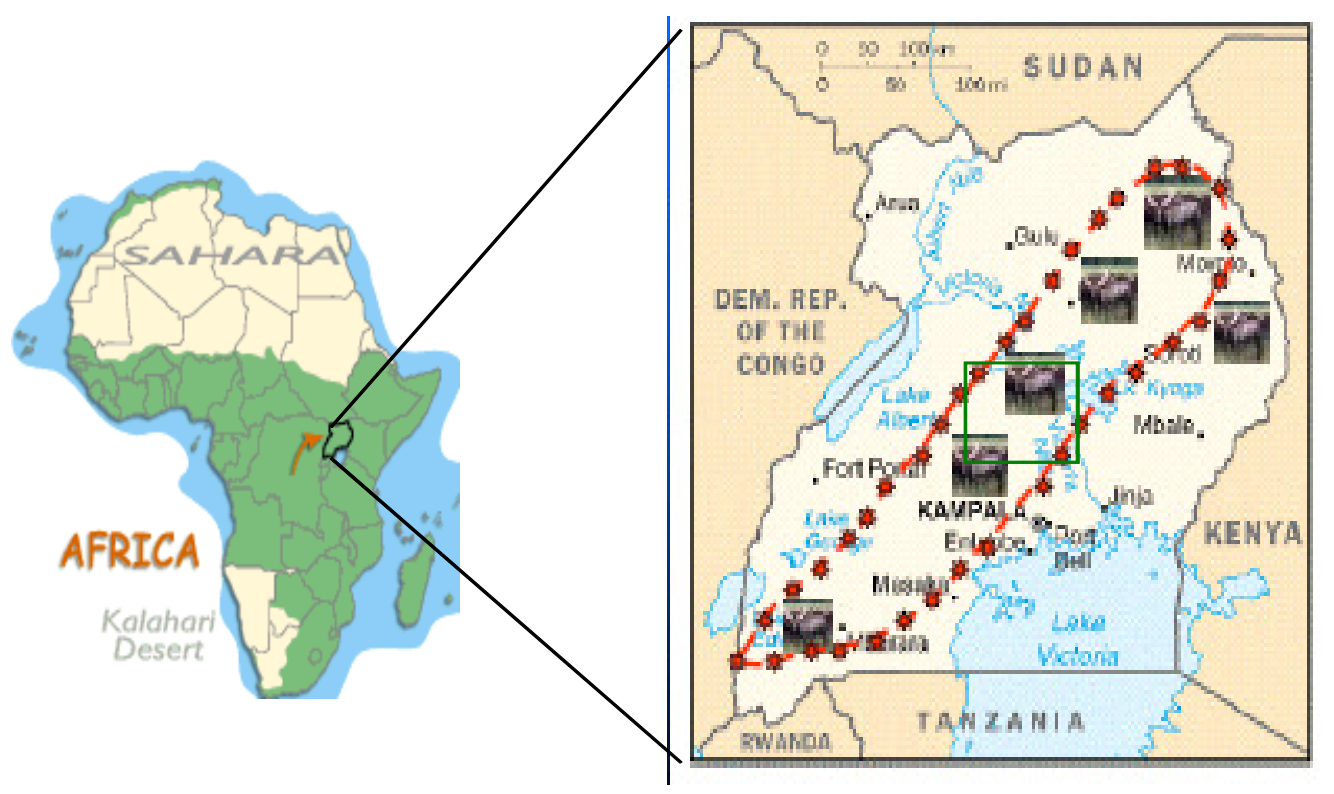

Figure 1. A map of Uganda showing the "Cattle corridor". 
climatic data. However, the daily rainfall and temperature data sets from Mbarara, Masindi and Soroti were nearly complete. They were hence selected for containing almost a full record of daily recordings unlike other weather recording stations in the region which had a lot of missing values. The exact location of Mbarara, Masindi and Soroti stations is indicated in Table 1.

\section{Data analysis}

\section{Rainfall variability index}

Rainfall and temperature variability was determined using standard variability index (SVI). In case of rainfall, SVI was computed as standardized precipitation departure from the long term mean. The index helps to separate the time series into different climatic regimes (Oguntunde, $e t$ al., 2011).

Rainfall variability index $(\delta)$ was then calculated as:

$\left.\delta_{\mathrm{i}}=\mathrm{P}_{\mathrm{i}}-\mu\right) / \sigma$

Where $\delta_{\mathrm{i}}$ is rainfall variability index for year $i, \mathrm{P}_{\mathrm{i}}$ is the annual rainfall for year $i$, $\mu$ and $\sigma$ are the mean annual rainfall and standard deviation for the period. Mean values and coefficient of variation $(\mathrm{CV})$ were also obtained to identify intra-station variability.

\section{Trend analysis}

Presence of monotonic trends was determined using non-parametric MannKendall test (Kendall, 1975) in XLSTAT. Mann- Kendall test statistics were more preferred because of their insensitivity to outliers which is common in climatological data. Significance of trends was determined at $95 \%$ confidence interval. For a given time series $X_{1}, X_{2}, X_{3} \ldots X_{n}$ given level of significance $\alpha$, the null hypothesis of no presence of trend in the time series is rejected if $\mathrm{Z}>\mathrm{Z}_{\alpha / 2}$. The null hypothesis $\mathrm{H}_{\mathrm{o}}$ is not rejected when $\mathrm{Z}_{\alpha / 2}$ at $\alpha$ level of significance $(\mathrm{P}<0.05)$. If $\mathrm{Z}$ is positive, then the trend is increasing and if $\mathrm{Z}$ is negative then the trend is decreasing. The Mann-Kendall test statistic $\mathrm{S}$ is specified in the model:

$$
S=\sum_{i=1}^{n-1} \sum_{j=i+1}^{n} \operatorname{sgn}(x j-x i)
$$

Where $\mathrm{n}$ is the length of the time series $\mathrm{x}_{\mathrm{i}, \ldots \ldots . . ., \mathrm{x}_{\mathrm{n}}}$ and $\operatorname{sgn}($.$) is a sign function, \mathrm{x}_{\mathrm{j}}$ and $x_{i}$ are values in the years $j$ and $k$ respectively.

$$
\operatorname{sgn}(y)=\left\{\begin{array}{c}
1 \text { if }(y>0) \\
0 \text { if }(y=0) \\
-1 \text { if }(y<0)
\end{array}\right.
$$

Table 1. Location of weather recording stations in the cattle corridor

\begin{tabular}{lccc}
\hline Station & Latitude & Longitude & Altitude (a. s. l) \\
\hline Mbarara & $-0.51^{\circ} \mathrm{S}$ & $30.6^{\circ} \mathrm{E}$ & $4600 \mathrm{ft}$ \\
Soroti & $1.70^{\circ} \mathrm{N}$ & $33.6^{\circ} \mathrm{E}$ & $3684 \mathrm{ft}$ \\
Masindi & $1.68^{\circ} \mathrm{N}$ & $31.7^{\circ} \mathrm{E}$ & $3781 \mathrm{ft}$ \\
\hline
\end{tabular}




\section{Determination of extreme indices}

Daily rainfall and temperature data were first checked for missing values and further observational checks were also made to ensure no outliers. Daily rainfall and temperature data was then subjected to RClimdex software for analysis following procedures as in Zhang and Feng (2004). Details of the procedures of running Rclimdex and the software are available at Expert Team on Climate Change Detection Indices (ETCCDI) website. RClimdex produces 29 annual time series indices as recommended by the Expert Team on ETCCDI. However, in this study we selected only five precipitation and temperature indices which are relevant for the cattle corridor (Table 2).

\section{Results}

\section{Rainfall and temperature characteristics}

Annual mean rainfall received was highest in Soroti (Table 3). Mbarara experienced the most unstable rainfall pattern with a coefficient of variation (CV) of $25 \%$ while the least variation was observed in Masindi. Sen's slope estimator revealed non-significant increasing rainfall trends in Mbarara and Soroti while in Masindi the rainfall trend was decreasing (Table 3).

Maximum and minimum temperatures continue to rise in all stations (Table 4). Mbarara and Soroti experienced increasing significant trends $(\mathrm{P}<0.05)$ in maximum temperatures while in Masindi the trend was increasing but not significant $(\mathrm{P}>0.05)$. Table 4 showed that minimum temperatures were also significantly increasing in Mbarara $(\mathrm{P}<0.01)$ and Masindi $(\mathrm{P}<0.05)$ while in Soroti there was an increasing trend in minimum

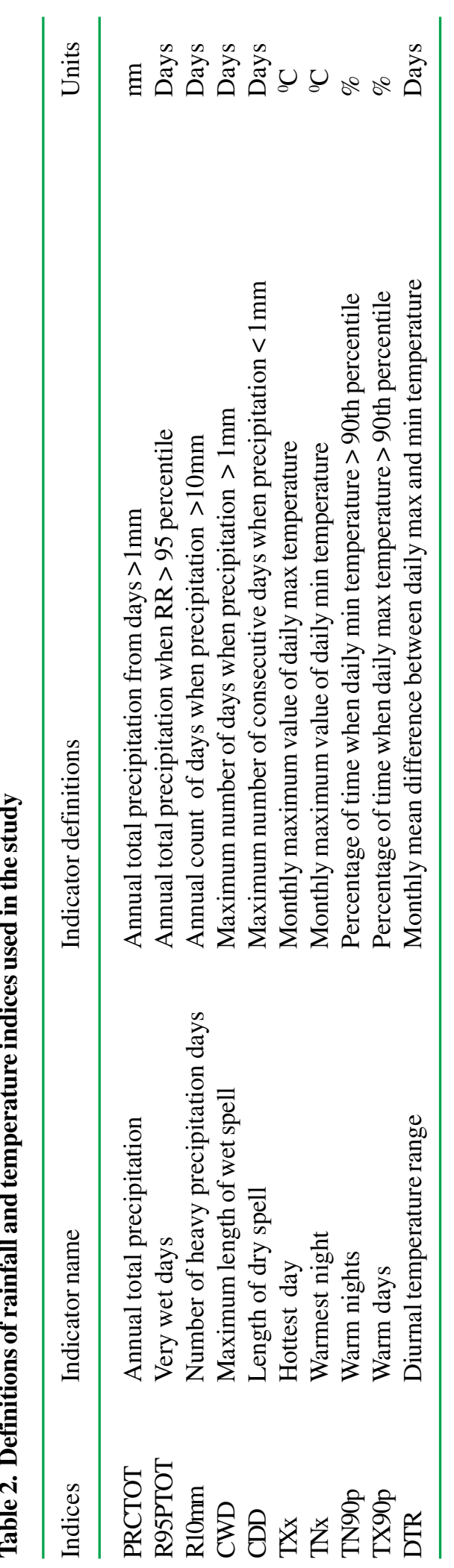


Table 3. Annual rainfall characteristics for Mbarara, Masindi and Soroti

\begin{tabular}{lcccc}
\hline Location & $\mathrm{n}$ & $\begin{array}{c}\text { Mean annual } \\
\text { rainfall }(\mathrm{mm})\end{array}$ & $\mathrm{CV}(\%)$ & Sen's slope estimator \\
\hline Mbarara & 51 & $1010 \pm 256.1$ & 25.3 & 5.278 \\
Masindi & 48 & $1359 \pm 175.9$ & 12.9 & -0.336 \\
Soroti & 53 & $1402 \pm 228.3$ & 16.3 & 0.370 \\
\hline
\end{tabular}

Table 4. Temperature characteristics for Mbarara, Masindi and Soroti

\begin{tabular}{llcllc}
\hline Location & \multicolumn{2}{c}{ Maximum temperature $\left({ }^{\circ} \mathrm{C}\right)$} & & \multicolumn{2}{c}{ Minimum temperature $\left({ }^{\circ} \mathrm{C}\right)$} \\
\cline { 2 - 3 } \cline { 5 - 6 } \cline { 5 - 6 } & Mean & Sen's slope estimator & & Mean & Sen's slope estimator \\
\hline Mbarara & $26.7 \pm 0.48$ & $0.0 .023^{* *}$ & & $14.5 \pm 0.92$ & $0.051^{* * *}$ \\
Masindi & $29.6 \pm 1.16$ & 0.061 & & $17.0 \pm 0.68$ & $0.023^{*}$ \\
Soroti & $30.8 \pm 0.99$ & $0.034^{*}$ & & $18.1 \pm 0.34$ & 0.008 \\
\hline
\end{tabular}

${ }^{*}$ Trend significant at $\alpha=0.05 .{ }^{* * *}$ Trend significant at $\alpha=0.01$

temperatures but not significant $(\mathrm{P}>$ $0.05)$.

\section{Rainfall variability}

\section{Annual rainfall variability}

Figure 2 revealed that since 1961 the amount of rainfall received in Mbarara, Masindi and Soroti varied considerably. However from 2007-2013 Mbarara experienced 7 wet years. The driest years in Masindi were 1983, 1985 and 1998. From 1965-1968, 1973- 1976 Masindi experienced 4 successive dry years while five successive dry years were experienced in 1982-1986 and 2001-2005. From 1961 until 2013 Soroti experienced 20 wet years and 32 dry years. From 1992-2013 Soroti experienced 15 dry years and only 5 wet years.

\section{Decadal rainfall variability}

In Mbarara the wettest decade was in 1970s while the driest decade was 1980s (Fig. 3). The driest decade for Masindi and Soroti was in 2000s. During the decade of 1990s, decadal deviation was below "normal" in all stations indicating that the region experienced slightly dry conditions. Decadal deviation for Mbarara from 2000-2009 was above normal and higher than any other decade since 1970 s (Fig. 3).

\section{Monthly rainfall variability}

Monthly rainfall in Masindi followed a perfect bi-modal rainfall pattern with maximum peaks in April and October throughout the 48 year period. However, the bi-modal rainfall pattern was slightly changing and three maximum rainfall 


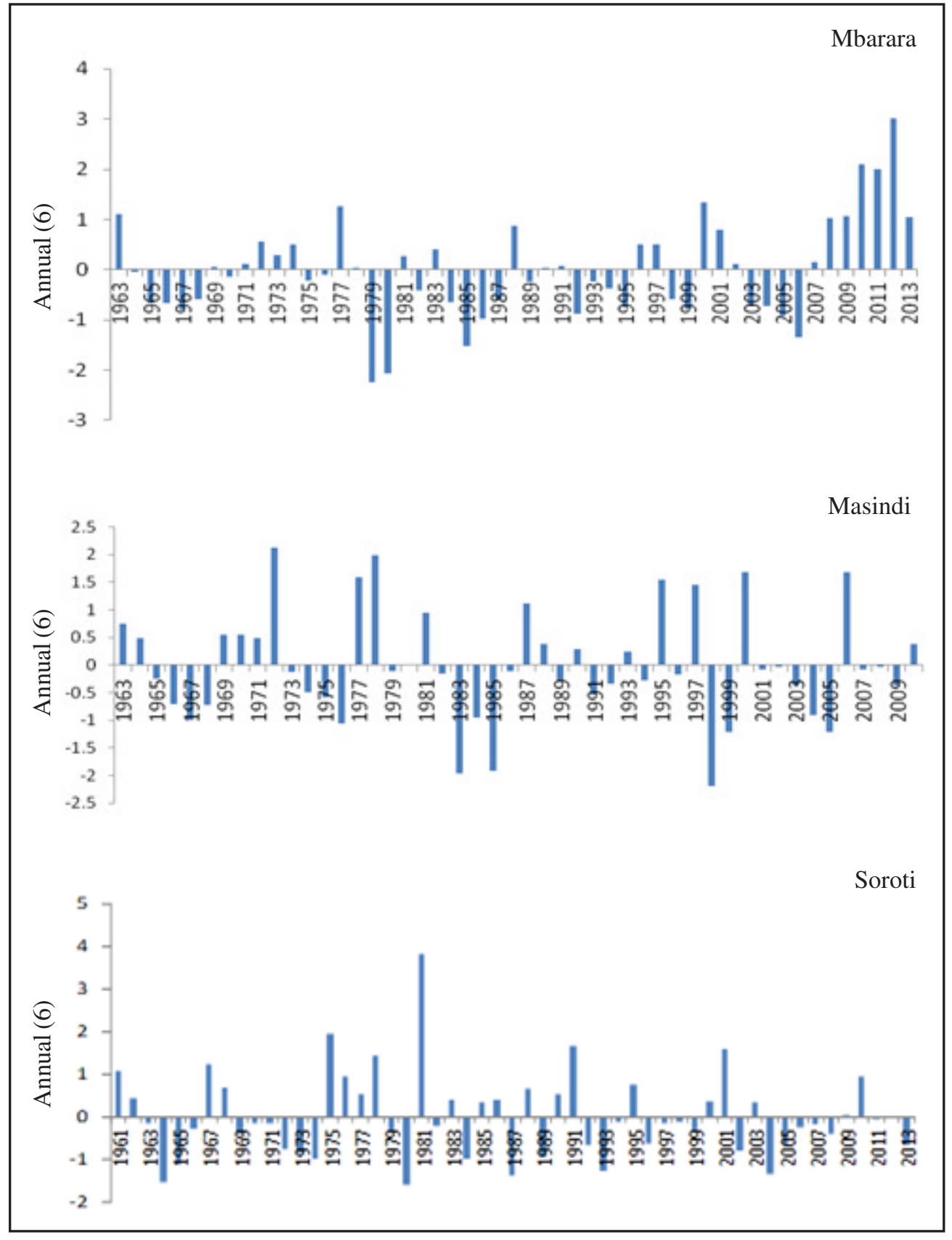

Figure 2. Annual rainfall variability for Mbarara, Masindi and Soroti. 
peaks emerge in Mbarara and Soroti. (PRCPTOT) showed weak nonFebruary - April (FMA) and August- significant increasing trends in all stations November were the wettest months while (Table 5). Heavy precipitation days ( $>$ June- July remained the driest months in $10 \mathrm{~mm}$ ) revealed weak declining trends all stations (Fig. 4).

\section{Trends in precipitation extremes}

The results of precipitation indices are shown in Table 5. Total annual precipitation which was not significant $(P>0.05)$ in Mbarara and Masindi. However, in Soroti heavy precipitation days were increasing. Heavy precipitation days were most frequent in 1978, 1981 and 2001 for

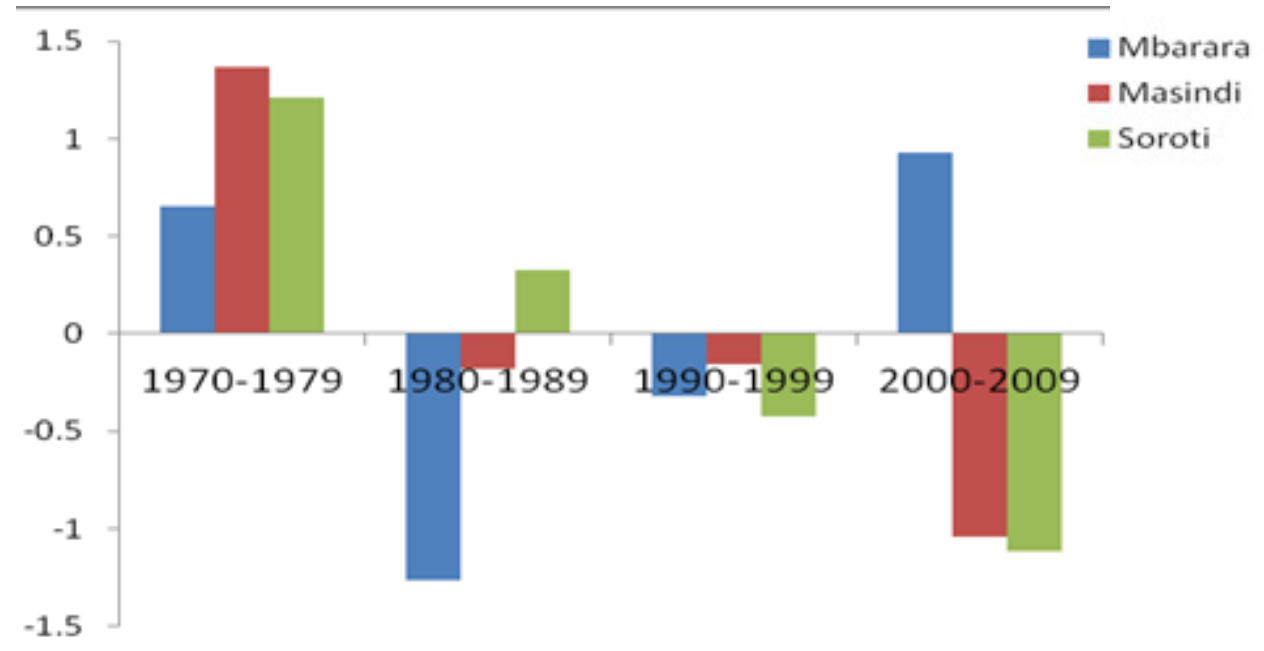

Figure 3. Decadal rainfall variability for Mbarara, Masindi and Soroti.

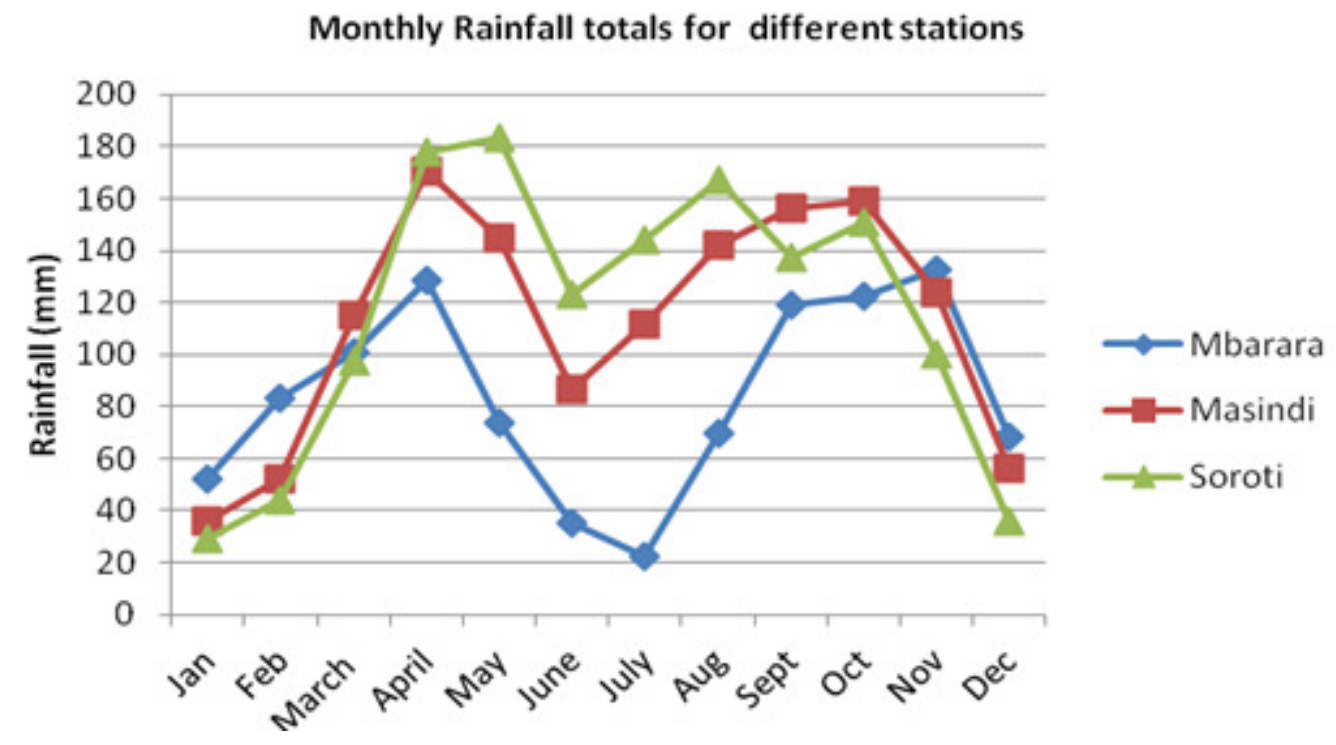

Figure 4. Monthly rainfall received in Mbarara, Masindi and Soroti. 
Mbarara, Soroti and Masindi respectively. Consecutive wet days (CWD) showed weak non-significant increasing trend only in Mbarara while in Masindi and Soroti CWD were declining (Table 5). Consecutive dry days (CDD) which measures for extremely dry days when precipitation is less than $1 \mathrm{~mm}$, showed weak decreasing trends in Mbarara while in Masindi the frequency of CDD showed significant decreasing trends $(P<0.05)$. In Soroti the frequency of CWD were reducing at a rate (0.091) higher than in Masindi (0.016). Frequency of CDD in Soroti showed strong significant increasing trends $(\mathrm{P}>0.05)$. Further analysis, revealed that in Mbarara the highest frequency of CDD was experienced during 1984, 1986 and 1991 while 1971, 1989 and 1991 were the years when Soroti experienced the highest frequencies of CDD.

\section{Trends in temperature extremes}

Table 6 revealed that frequency of hottest days (TXx) in Soroti was significantly increasing $(\mathrm{P}<0.05)$ while the number of warmest days (TXn) was slightly reducing. In Mbarara and Masindi the number of warmest nights was also significantly increasing $(\mathrm{P}<0.05)$ indicating that the daily minimum temperatures recorded at night since 1960 were rising (Table 6). TXx which is a measure of the monthly maximum value of daily maximum temperatures experienced in 2000s were significantly higher than those recorded in 1960s.

Most stations experienced significant increases in hot days except Soroti where

Table 5. Extreme precipitation indices for Mbarara, Masindi and Soroti

\begin{tabular}{lccc}
\hline Index & Mbarara & Masindi & Soroti \\
\hline Total annual precipitation (PRCPTOT) & 0.176 & 4.196 & 3.789 \\
Consecutive wet days (CWD) & 0.026 & -0.016 & -0.091 \\
Maximum Consecutive dry days (CDD) & -0.005 & $-1.119^{*}$ & $0.822^{*}$ \\
Annual count of days when PRCPe"10mm(r10mm) & -0.084 & -0.062 & 0.06 \\
Simple precipitation intensity index (SDII) & 0.004 & -0.004 & 0.052 \\
\hline
\end{tabular}

*Trend significant at the $5 \%$ level

Table 6. Extreme temperature indices for Mbarara, Masindi and Soroti

\begin{tabular}{lccc}
\hline Index & Mbarara & Masindi & Soroti \\
\hline Percentage Hot days (TX90p) & $0.418^{*}$ & $0.49^{*}$ & 0.463 \\
Percentage Warm nights (TN90p) & $0.684^{*}$ & $0.954^{*}$ & -0.172 \\
Hottest days (TXx) & 0.032 & 0.091 & $0.054^{*}$ \\
Warmest nights (TNx) & $0.108^{*}$ & 0.057 & -0.023 \\
Diurnal temperature range (DTR) & $-0.065^{*}$ & -0.047 & $0.055^{*}$ \\
Warm spell duration Index (WSDI) & 0.114 & $0.276^{*}$ & 0.235 \\
\hline
\end{tabular}

${ }^{*}$ Trend significant at the $5 \%$ level 
the trend was increasing but not significant $(\mathrm{P}<0.05)$. Frequencies of warm nights were also increasing except in Soroti where there was a decline in the frequency of warm nights. Daily minimum temperatures, Tx were warming faster than daily maximum temperatures throughout all stations. The lowest rate of temperature increase in warm nights $(0.43$ ${ }^{0} \mathrm{C}$ ) was observed in Soroti while Mbarara experienced the highest rate of about $0.68^{\circ}$ $\mathrm{C}$ year $^{-1}$. Percentage hot days were increasing at a rate of $0.42,0.49,0.46^{\circ} \mathrm{C}$ per year in Mbarara, Masindi and Soroti respectively. Mean maximum temperatures in 1960s were lower compared to those recorded in 2000s in all locations showing that there has been a persistent steady increase in day hot temperatures and cold night temperatures in the entire cattle corridor (Table 6). DTR showed significant decreasing trends in Mbarara and Masindi $(\mathrm{P}<0.05)$ however, in Soroti the trend was significantly increasing $(\mathrm{P}<0.05)$.

\section{Discussion}

The amount of rainfall received per year varied considerably in all stations. Positive increasing rainfall trends were found in Mbarara and Soroti while in Masindi the trend was decreasing (Table 3). The highest coefficient variation $(25 \%)$ in annual rainfall received was observed in Mbarara while Masindi had the least CV (Table 3). This indicates that the rainfall patterns in Masindi were relatively stable compared to Mbarara and Soroti. Decadal and annual rainfall deviation also revealed high levels of variability. Most decades were dry except 1970s which were wet in all stations. The most dry and wet decade for Mbarara was 1980s and 2000s respectively. Similar to our findings,
Nimusiima et al (2013) reported serious prolonged drought spells in 1991-2000. Perhaps this variability can be attributed to the influence of inter-tropical convergence zone, the Zaire airy boundary and El Niño - Southern Oscillation (ENSO) with teleconnections to pacific and surface sea temperatures (Nicholson, 1996). Extreme rainfall indices revealed mixed results. Total annual wet days (PRCPTOT) were increasing but not significant in all stations. Heavy precipitation days were also on the rise in all stations but not significant. However, consecutive wet days, CWDs were only significantly increasing in Mbarara while in Masindi and Soroti they were decreasing. Simple precipitation intensity index was increasing in Mbarara and Soroti while in Masindi it was decreasing. Consecutive dry days, CDDs were significantly increasing in Soroti while in Mbarara and Masindi CDDs were decreasing. CDDs are a measure for extremely dry days (Klein Tank et al., 2009). The study further revealed that severe dry periods were experienced during 1979/80, 1983, 1989, and 1998 in most cattle corridor areas (Fig. 2). A study by Stampone et al (2011), revealed similar findings that there has been an increase in the occurrence of droughts of which 1991-2000 decade recorded the highest frequency of droughts. Mduma et al., (1999) observes that vegetation and rainfall are positively correlated. This implies that increased frequency of CDD negatively affects availability of grazeable pastures hence compromising survival of livestock. Results from the study are also consistent with those earlier reported by Makuma-massa et al (2010) that the cattle corridor experienced severe droughts of 1980 to 1983,1990 to 1992 and 1996 to 2000. The same authors 
further reported that there were outbreaks of Foot and mouth disease (FMD) and contagious Bovine during those severe drought periods. The decreasing number of wet days coupled with significant increases in CDDs indicates that Soroti district and her adjacent areas which are situated in the North east of the cattle corridor are getting drier while the southwest in Mbarara it's slightly getting wetter.

Maximum and minimum temperatures showed increasing trends in all stations indicating that the entire cattle corridor continues to experience raising temperatures. However maximum temperatures showed significant trends $(\mathrm{P}$ $<0.05)$ in Mbarara and Soroti. Daily minimum temperatures continued to rise and were significantly increasing in Mbarara and Masindi. Our findings are consistent with climate models which suggest that most of the areas in Uganda by 2050 will experience a rise in high temperatures in the warmest month of between $2^{\circ}$ and $2.5^{\circ} \mathrm{C}$ (Bashaasha et al., 2013). These results also compare well with global projections (Narayanan et al., 2013; Oguntunde, et al., 2011; IPCC, 2007). Keggenhoff, et al. (2014) also reported similar findings of significant warming trends in the Georgia. Temperature extreme indices revealed strong significant increasing trends in mean daily maximum temperatures. Percentage of days/time when daily maximum temperatures, TX and daily minimum temperatures, $\mathrm{TN}>90^{\text {th }}$ percentile were significantly increasing $(\mathrm{P}<0.05)$. DTR was significantly increasing in Soroti while in Masindi was decreasing though not significant and in Mbarara DTR was significantly decreasing. Daily minimum temperatures were warming faster at an average rate of $0.9^{\circ} \mathrm{C}$ per year than daily maximum temperatures ranging at an average of about $0.4{ }^{\circ} \mathrm{C}$. These results are consistent with studies that reported a shift in higher temperature values since the middle of the $21^{\text {st }}$ century (Donat $e t$ al 2013; Donat and Elexander 2012). Mudson et al., 2005 suggests that livestock productivity parameters like conception rates decline as result of increased temperatures. Hanson et al 1993 observed that sustained increase in mean temperatures will result into significant changes in species distribution, composition patterns and biome distribution. Further still, Rowlison 2008 observed a reduction in feed intake of farm animals because of heat distress as a result of increased temperatures. Reduced feed intake directly results into poor growth and performance of animals. Stem et al. (1989), observed that climatic restrictions on vectors, environmental habitats, and disease causing agents are important for keeping many animal diseases in check. All life processes function within a desirable temperature range. The observed raising temperatures in the cattle corridor will most likely alter the existing agro-ecological systems and increase heat stress to existing livestock species and consequently lowering productivity.

\section{Conclusion}

It was evident from the study that annual total wet days were increasing in all stations but not significant $(\mathrm{P}>0.05)$ while consecutive wet days (CWDs) were only increasing in Mbarara Consecutive dry days (CDDs) revealed weak declining trends in Mbarara and stronger significant increasing trends in Soroti $(\mathrm{P}<0.05)$. In all stations the amount of annual rainfall 
received varied highly. All temperature extreme indices indicate that the cattle corridor continues to experience warming conditions. The observed increasing temperatures, coupled with declining CWDs and increasing CDDs will most likely result into; (i) increase in heat stress to livestock (ii) drying of surface water sources and (iii) changes in pasture species composition thus causing a decline in livestock productivity. Therefore promotion of livestock species which are tolerant to heat stress, sustained supply of pasture species tolerant to warming conditions while increasing utilization of available crop residues as animal feeds, and increasing opportunities for water harvesting and conservation may offer an excellent adaptation package to improve livestock production.

\section{Acknowledgement}

The authors are grateful to the German Academic Exchange Service (DAAD) in partnership with International Livestock Research Institute (ILRI) for funding this study. Special thanks to the Department of Metereology, Ministry of Water and Environment for availing us rainfall and temperature data sets.

\section{References}

Bashaasha, B., T. S. Thomas, M. Waithaka, and M. Kyotalimye. 2013. Chapter 12 in East African Agriculture and Climate Change: A Comprehensive Analysis. Waithaka, M., N.C. Gerald, T.S.Timothy, and M. Kyotalimye (eds.). International Food Policy Research Institute. DOI: http:// dx.doi.org/10.2499/9780896292055

CCSP (Climate Change Science Program), 2008: Weather and Climate
Extremes in a Changing Climate. Regions of Focus: North America, Hawaii, Caribbean, and U.S. Pacific Islands. A Report by the U.S. Climate Change Science Program and the Subcommittee on Global Change Research. [Thomas R. Karl, Gerald A. Meehl, Christopher D. Miller, Susan J. Hassol, Anne M. Waple and William L. Murray (eds.). Department of Commerce, NOAA's National Climatic Data Center, Washington, D.C., USA, $164 \mathrm{pp}$.

Donat M. G., L. V. Alexander, H. Yang, I. Durre, R. Vose, R. J. H. Dunn, K. M. Willett, E. Aguilar, M. Brunet, J. Caesar, B. Hewitson, C. Jack, A. M. G. Klein Tank, A. C. Kruger, J. Marengo, T. C. Peterson, M. Renom, C. Oria Rojas, M. Rusticucci, J. Salinger, A. S. Elrayah,S. S. Sekele, A. K. Srivastava,B. Trewin,C. Villarroel, L. A. Vincent, P. Zhai, X. Zhang and S. Kitching. 2013. Updated analyses of temperature and precipitation extreme indices since the beginning of the twentieth century: The HadEX2 dataset, J. Geophys. Res. Atmos.,118, doi:10.1002/jgrd.50150

Donat M. G. and L. V. Alexander 2012. The shifting probability distribution of global daytime and night-time temperatures, Geophysical Research Letters, 39, L14707, 5 doi:10.1029/ 2012 GL052459.

Hanson, J, D., B.B. Baker and R. M. Bourdon. 1993. Comparison of the effects of different climate change scenarios on rangeland livestock production. Agricultural Systems 41:487-802.

IPCC (Intergovernmental Panel on Climate change), 2007. Climate Change 2007: Impacts, adaptation and vulnerability. Contribution of Working 
Group II to the Fourth Assessment Report of the Intergovernmental Panel on Climate Change, M.L. Parry, O.F. Canziani, J.P. Palutikof, P.J. van der Linden and C.E. Hanson, eds.

Keggenhoff, I.,M. Elizbarashvili, A. AmiriFarahani, and L. King. 2014. Trends in daily temperature and precipitation extremes over Georgia, 1971-2010. Weather and Climate Extremes 4:7585.

King, A. 2002. Joint donor agencies study on the performance of and growth prospects for strategic exports in Uganda: Case study on livestock, hides, skins and leather products. Kampala: European Commission.

Klein Tank, A.M.G., F.W. Zwiers and X. Zhang. 2009. Guidelines on analysis of extremes in a changing climate in support of informed decisions for adaptation. World Meteorological Organisation (WMO), 2009.

Makuma-Massa, H. J.G.M, Majariwa, P. Isubikalu, S. Tumuhairwe and P. Mukwaya . 2010. Pastoral adaptation strategies to climate change in selected areas of the cattle corridor. Second RUFORUM Biennial Meeting 20-24 September 2010, Entebbe, Uganda.

Mduma, S.A.R., Sinclair, A.R.E. and Hilborn, R. 1999. Food regulates the Serengeti wildebeest: a 40-year record. Journal of Animal Ecology 68:101112.

MLWE (Ministry of Lands, Water and Environment), 2003. "Water Sector Reform: Water for Production Component - Water for Production Strategy 2003 - 2015".

Moberg, A. and P. D. Jones. 2005. Trends in indices for extremes in daily temperature and precipitation in Central and Western Europe, 1901-
99. International Journal of Climatology, v. 25, p. 1149-1171, 2005. Nandintsetseg. B., J. S. Greene and C. E. Goulden. 2006. Trends in extreme daily precipitation and temperature near Lake H"ovsg"ol, Mongolia. International Journal of Climatology; 27: 341-347 (2007) Published online 25 September 2006 in Wiley InterScience (www.interscience. wiley.com) DOI: 10.1002/joc. 1404

Narayanan, P., A. Basistha, S. Sarkar and K. Sachdeva. 2013. Trend analysis and ARIMA modelling of pre-monsoon rainfall data for western India. C. R. Geoscience 345:22-27. Elsevier

Nicholson, S.E. 1996. A review of climate dynamics and climate variability in Eastern Africa. Journal of the Limnology, Climatology and Paleoclimatology of the East African Lakes. pp. 25-56.

Nimusiima A., C.P.K Basalirwa, J.G.M. Majaliwa, W. Otim-Nape W, J. OkelloOnen J., C. Rubaire-Akiiki, J. KondeLule and S. Ogwal-Byenek. 2013. Nature and dynamics of climate variability in the Uganda cattle corridor. African Journal of Environmental Science and Technology (8):770-782.

Oguntunde, P. G., J. A. Babatunde and G. Lischeid. 2011. Rainfall trends in Nigeria, 1901-2000. Journal of Hydrology 411:207-218. Elsevier

Reed, D. N., T. M. Anderson, J. Dempewolf, K. Metzger and S. Serneels. 2009. The spatial distribution of vegetation types in the Serengeti ecosystem: the influence of rainfall and topographic relief on vegetation patch characteristics. Journal of Biogeography 36(4):770-782.

Rowlinson, P. 2008. Adapting Livestock Production Systems to Climate Change 
- Temperate Zones. Livestock and Global Change Conference Proceedings. May 2008, Tunisia.

Santos, C. A. C. 2011. Trends in indices for extremes in daily air temperature over Utah, USA. Revista Brasileira de Meteorologia 26(1):19 - 28.

Stampone, D. M., Hartter, J., Chapman, A. C. and Ryan, J.S. 2011. Trends and Variability in Localized Precipitation Around Kibale National Park, Uganda, Africa. Research Journal of Environment and Earth Sciences, 3(1): 14-23.

Stem, E., G.A. Mertz, J.D. Stryker, and M. Huppi., 1989. Changing animal disease patterns induced by the greenhouse effect. In: The Potential Effects of Global Change on the United States: Appendix $C-$ Agriculture, Volume 2. J. Smith and D.A. Tirpack (eds). US Environmental Protection Agency, Washington, D.C., pp. 11-1 to 11-38.

Thornton, P.K, P.G. Jones, T.Owiyo, R.L Kruska, M.Herrero, V. Orindi, S. Bhadwal, P. Kristjanson, A. Notenbaert, N. Bekele and A. Omolo., 2008. Climate change and Poverty in
Africa. Mapping hotspots of vulnerability. AfJARE. Volume 2 No 1 March 2008.

Thornton, P.K., J.van de Steeg, A. Notenbaert and M.Herrero. 2009. The impacts of climate change on livestock and livestock systems in developing countries: A review of what we know and what we need to know. Global Environ. Change (2009), doi:10.1016/ j.gloenvcha.2009.05.002

Toreti, A., and F. Desiato. 2008. Changes in temperature extremes over Italy in the last 44 years. International Journal of Climatology 28:733-745.

Uganda Bureau of Statistics 2002. The 2002 Uganda Population and Housing Census, Population Size and Distribution" Kampala, Uganda

Wang, X. L. and Feng, Y. 2009. RHtestsV3 User Manual. Climate Research Division, Science and Technology Branch, Environment Canada. 26 pp.

Zhang, X and Y. Feng. 2004. RclimDex User manual. Climate Research Division, Science and technology Branch, Environment Canada. 23pp. 